\title{
Survival of Pelagic Juvenile Loggerhead Turtles in the Open Ocean
}

\author{
CHRISTOPHER R. SASSO, ${ }^{1}$ National Marine Fisheries Service, Southeast Fisheries Science Center, 75 Virginia Beach Drive, Miami, FL 33149, USA \\ SHERYAN P. EPPERLY, National Marine Fisheries Service, Southeast Fisheries Science Center, 75 Virginia Beach Drive, Miami, FL 33149, USA
}

\begin{abstract}
We deployed pop-up archival transmitting tags on 15 loggerhead sea turtles (Caretta caretta) that had been lightly hooked in the United States pelagic longline fishery and on 10 loggerheads that we dip-netted off the surface to serve as controls in the North Atlantic Ocean. We received data from tags of 10 lightly hooked turtles and 7 control turtles. We used data transmitted by the tags in a known-fate model to estimate annual survival rates and determine if there were differences in survival between the 2 groups. The best model indicates there is no difference in survival between the lightly hooked and control turtles, and the estimated annual survival rate was $0.814(95 \% \mathrm{CI}=0.557-$ 0.939). Our results suggest that when all fishing gear is removed lightly hooked turtles may not suffer any additional mortality relative to control turtles. (JOURNAL OF WILDLIFE MANAGEMENT 71(6):1830-1835; 2007)
\end{abstract}

DOI: $10.2193 / 2006-448$

KEY WORDS Atlantic Ocean, Caretta caretta, known-fate model, loggerheads, pelagic survival.

Sea turtles are long-lived species that spend virtually their entire lives at sea. Given the difficulty of obtaining and sampling all life stages of these species, population models are often employed to provide insight into the status of the species (Heppell et al. 2003, Dutton et al. 2005, Heppell et al. 2005). Loggerhead sea turtles (Caretta caretta) have been the subject of numerous modeling efforts (Crouse et al. 1987, Crowder et al. 1994, National Marine Fisheries Service 2001, Chaloupka 2003, Heppell et al. 2003), but all these efforts lacked an empirical estimate of survival in the pelagic oceanic stage and were compelled to use an inferred value.

Overall survival in the pelagic oceanic stage is a function of both natural and fishing mortality rates. The major source of fishing mortality in the open ocean is the pelagic longline fishery, which is known to unintentionally capture large numbers of sea turtles (Lewison et al. 2004) and has been implicated in the decline of some populations (Hays et al. 2003).

Although the number of longline fishery interactions have been estimated (Lewison et al. 2004), most loggerheads are released alive and the posthooking mortality associated with the interactions is not known. Thus, there is a need for estimates of total survival and of any reduction in survival related to fishery interactions. Despite the lack of direct estimation of survival rates, decisions on the management of the United States pelagic longline fishery relative to its impact on loggerheads have been made (Federal Register 2004) and suggestions of the varying levels of increased mortality due to hook location and gear removal were created (Ryder et al. 2006).

There have been a few studies that assessed survival of oceanic sea turtles or the impact of longline interactions on sea turtles. Bjorndal et al. (2003) used a catch curve analysis to estimate pelagic survival for loggerhead turtles. Chaloupka et al. (2004) compared differences in survival for 40

${ }^{1}$ E-mail: chris.sasso@noaa.gov loggerheads that had either swallowed hooks (hooked in esophagus or stomach) or were lightly hooked (hooked in mouth or externally or entangled) and found no difference after 90 days. Swimmer et al. (2006) compared the behavior of longline-caught and dip-netted control olive ridley (Lepidochelys olivacea; $n=11$ ) and green turtles (Chelonia mydas; $n=1$ ) for up to 115 days and found no differences in behavior or length of deployment between the treatment and control turtles.

As demonstrated by Chaloupka et al. (2004) and Swimmer et al. (2006), satellite tags are useful to assess survival and the impact of fishery interaction but these data do present some challenges for such analyses. For example, determining the fate of an animal from transmitted data is problematic, as is the interpretation of transmission failure. Nonetheless, it is likely to be the best and only way to estimate survival in situ of sea turtles in the open ocean. Studies using conventional satellite tags, such as Chaloupka et al. (2004) and Hays et al. (2003), are limited to modeling time to transmission failure, rather than survival rates, because turtle mortality and failure rates are confounded.

To have exact knowledge of the fate of an individual and the reason for tag failure, the particular individual would need to be retrieved. However, this is not practical in the open ocean. Pop-up archival transmitting tags (PAT) are an alternative to conventional satellite tags and are well-suited to survival studies of open-ocean animals (Domeier et al. 2003, Horodysky and Graves 2005). The PAT tags are programmed to release themselves from the animal after a planned duration and then to transmit the data. The buoyancy of the PAT tags, transmission of depth data, temperature data, and the ability to transmit when prematurely released can provide greater insight into the fate of an individual than can conventional satellite tags. In contrast to conventional satellite tags, which are used to assess time to failure, PAT tags are used to assess time to a specific event (i.e., pop-up).

Two distinct advantages of the PAT tags are 1) the 
programmed premature release of a PAT tag after remaining at a constant depth indicates whether the turtle has been submerged without surfacing to breathe or is floating for an extraordinary amount of time at the surface (neither are normal behaviors), and 2) the transmitted dive data allow for the observation of dive behaviors indicative of a compromised individual. Data from PAT tags can provide insight into the fate of a turtle with 3 possible outcomes: 1) survival of the entire duration of the planned deployment, 2) presumed death (e.g., remained at a constant depth for the programmed premature release period, went below $1,500 \mathrm{~m}$, or exhibited dive behavior indicative of a compromised individual that gradually reduces diving over several days until the turtle is only floating at the surface), or 3) inconclusive fate (e.g., the turtle appeared to be diving normally but the tag became detached or popped-up for an unknown reason). Even in the case where fate cannot be determined, useful information that the turtle was alive until a known date is acquired.

In order to assess pelagic survival of loggerhead turtles in the open ocean and the effect of fisheries interactions on survival, we initiated a study to deploy PAT tags on loggerheads in the North Atlantic to determine whether survival was different between turtles that had interacted with the fishery and turtles that were captured independent of the fishery.

\section{STUDY AREA}

We captured loggerheads in the north-central North Atlantic during experiments to evaluate ways to reduce sea turtle bycatch in pelagic longline fisheries (Bolten et al. 2004, Watson et al. 2005). Turtles were captured off the Grand Banks (an area of underwater plateaus southeast of Newfoundland) and to the east of the Azores, in waters typically $>600 \mathrm{~m}$. These areas are highly productive due to the interactions between the warm Gulf Stream and the cold Labrador Current.

\section{METHODS}

We trained observers to deploy 39 PAT tags (Wildlife Computers, Inc., Redmond, WA) on loggerheads that had either interacted with the pelagic longline fishery (hooked or entangled) or had been directly captured using a dip-net during the late summer and early autumn in 2001,2002, and 2003. These PAT tags, comprising Versions 2, 3, and 4 (Table 1), transmitted time-at-depth and time-at-temperature histograms, depth-temperature profiles, and lightlevel curves. We measured turtles with calipers (nearest 0.1 $\mathrm{cm}$ ) from the nuchal notch to the notch between the 2 postcentral scutes to obtain minimum straight carapace length.

The observers secured PAT tags to turtles via a $10-\mathrm{cm}$ tether attached to an eyestrap, which we secured to bones underlying the postcentral scutes with 2 bolts (Epperly et al., in press $b$ ). They deployed PAT tags on 15 turtles lightly hooked and on 10 turtles that we captured with dip nets to serve as controls. In addition, they deployed 10 PAT tags on turtles that had swallowed the hook (hooked in the esophagus or stomach) and 4 tags on turtles entangled but not hooked in longline gear, but we did not include these 14 individuals in these analyses due to high transmission failure and small sample sizes. Observers removed all hooks and line from turtles with the exception of swallowed hooks, which we left in place after removing as much line as possible.

We programmed PAT tags to prematurely release if the tag remained at a constant depth ( $\pm 2 \mathrm{~m}$ with no outliers) for 4 days (PAT tag Version 2) or for 8 days (PAT tag Version 3 and 4). In addition, to avoid reaching a crush depth, a device (RD-1500; Wildlife Computers, Inc., Redmond, WA) would sever the tether if the tag descended below 1,500 m. Loggerheads are not known to dive to depths of 1,500 m (Polovina et al. 2004) and depth below that would imply a dead turtle descending to the bottom. Transmission began after the tag ascended and remained at the surface for the specified number of days $(4 \mathrm{~d}$ or $8 \mathrm{~d})$.

\section{Statistical Analyses}

We tested differences in carapace length and time spent at the surface between the treatment and control groups using a $t$-test in Microsoft Excel (Microsoft, Redmond, WA). As the longest planned and realized deployment was 12 months and annual survival was the parameter of interest, we created a 12-month capture history that accounted for the fate of the individual during each month for which we had data. In a given month, individuals could have survived, died, or had an unknown fate. For realized deployments $<12$ months (e.g., premature releases or data was transmitted for a shorter programmed deployment) data were right-censored. We created 2 sets of capture histories, one by year captured (2001, 2002, or 2003) to determine if survival varied among years, and the other by impact category (control or lightly hooked). We did not create a combined treatment by year history because we tagged all controls in 2004 and sample sizes were small for the lightly hooked turtles in 2003 and 2004 (Table 1). We used capture histories to estimate monthly and annual survival with the known-fate model from program MARK (White and Burnham 1999).

We ran 4 models for both the year and impact category capture histories in MARK: 1) survival by treatment group and time period, $\mathrm{S}(\mathrm{g} \times \mathrm{t}) ; 2)$ survival by treatment group and constant across time, $\mathrm{S}(\mathrm{g}) ; 3)$ survival by time period and no treatment groups $\mathrm{S}(\mathrm{t})$; and 4) survival constant for time and no treatment groups, $\mathrm{S}($.$) . We used Akaike's Information$ Criterion adjusted for small sample sizes $\left(\mathrm{AIC}_{c}\right)$ to rank the models and determine which model was best for the data, with lower $\mathrm{AIC}_{c}$ values and higher $\mathrm{AIC}_{c}$ weights indicating a more appropriate model (Hurvich and Tsai 1989; Burnham and Anderson 1992, 1998).

\section{RESULTS}

Of the 10 PAT tags on control turtles, 2 tags failed to transmit, 1 turtle died (based on dive behavior), 1 tag released prematurely with the fate unknown, and 6 tags remained attached for their programmed deployments 
Table 1. Pop-up archival transmitting tags (PAT) deployments for lightly hooked (with hook location noted) loggerhead turtles and for control animals that were dip-netted from the surface in the north-central Atlantic, 2001-2003.

\begin{tabular}{|c|c|c|c|c|c|}
\hline PAT version & Release date & Time programmed to be at large (d) & Time actually at large (d) & Hook location & Fate \\
\hline 2 & 2 Sep 2001 & 316 & 316 & mouth, lower jaw & survived \\
\hline 2 & 3 Sep 2001 & 315 & 315 & mouth, lower jaw & survived \\
\hline 2 & 6 Sep 2001 & 329 & 137 & flipper & unknown \\
\hline 2 & 12 Sep 2001 & 323 & 203 & beak & unknown \\
\hline 2 & 25 Sep 2001 & 310 & 160 & beak & unknown \\
\hline 2 & 3 Oct 2001 & 302 & 302 & flipper & survived \\
\hline 2 & 18 Oct 2001 & 270 & 177 & mouth, lower jaw & died \\
\hline 2 & 14 Aug 2002 & 284 & 10 & beak & died \\
\hline 2 & 6 Sep 2002 & 261 & 261 & tongue & survived \\
\hline 2 & 3 Oct 2002 & 234 & & mouth, side & no transmission \\
\hline 2 & 7 Oct 2002 & 230 & 230 & shoulder & survived \\
\hline 2 & 12 Oct 2002 & 225 & 225 & mouth, side, not in joint & survived \\
\hline 3 & 3 Sep 2003 & 365 & 365 & mouth, upper jaw & survived \\
\hline 3 & 5 Oct 2003 & 45 & 45 & flipper & survived \\
\hline 4 & 13 Oct 2003 & 355 & & flipper & no transmission \\
\hline 3 & 27 Sep 2003 & 51 & 51 & control & survived \\
\hline 4 & 1 Oct 2003 & 365 & 305 & control & unknown \\
\hline 4 & 1 Oct 2003 & 365 & 67 & control & died \\
\hline 4 & 1 Oct 2003 & 365 & & control & no transmission \\
\hline 4 & 1 Oct 2003 & 365 & & control & no transmission \\
\hline 4 & 1 Oct 2003 & 365 & 365 & control & survived \\
\hline 4 & 1 Oct 2003 & 365 & 365 & control & survived \\
\hline 4 & 1 Oct 2003 & 365 & 365 & control & survived \\
\hline 4 & 1 Oct 2003 & 365 & 365 & control & survived \\
\hline 4 & 1 Oct 2003 & 365 & 365 & control & survived \\
\hline
\end{tabular}

(Table 1). For the lightly hooked turtles, 2 tags failed to transmit, 2 turtles died (one based on dive behavior and one remained at a constant depth for 4 d), 3 tags released prematurely with the fate unknown, and 8 turtles survived for their programmed deployments (Table 1). As indicated by tags that transmitted, there was no difference in time spent at the surface $(\leq 1 \mathrm{~m})$ between control and lightly hooked turtles $(P=0.94)$. Mean proportion of time spent at the surface was $0.47(95 \% \mathrm{CI}=0.41-0.52)$ for control turtles and $0.47(95 \% \mathrm{CI}=0.40-0.54)$ for lightly hooked turtles. There was no size difference between control and lightly hooked turtles $(P=0.12)$. Mean straight carapace length was $52 \mathrm{~cm}$ with a range of $43-60 \mathrm{~cm}$.

For the suite of models examining a year effect, the best model indicated survival did not vary among years (S(.); $\mathrm{AIC}_{c}=32.26$, model wt $=0.85$, deviance $\left.=13.834\right)$. This model was 5.4 times more likely than the second-ranked model, which provided survival estimated by year $(\mathrm{S}(\mathrm{g})$; $\mathrm{AIC}_{c}=35.65$, model $\mathrm{wt}=0.15$, deviance $\left.=13.105\right)$.

For the models comparing control versus lightly hooked turtles (Table 2), survival did not vary between the 2 groups with the constant survival model being the best $\left(\mathrm{S}(.) ; \mathrm{AIC}_{c}=\right.$ 32.437). The model for survival by group was the secondranked model $\left(\mathrm{S}(\mathrm{g}) ; \mathrm{AIC}_{c}=34.378\right)$ but the constant survival model was 2.6 times more likely than survival varying between control and lightly hooked turtles (Table 2). The estimate of monthly survival for the constant survival model was $0.98(95 \% \mathrm{CI}=0.95-0.99)$ and annual survival was estimated to be $0.81(95 \% \mathrm{CI}=0.55-0.94$; Table 3). Although less likely than the constant survival model, the survival by group model estimated annual survival for controls as $0.85(95 \% \mathrm{CI}=0.41-0.98)$ and for lightly hooked as $0.78(95 \% \mathrm{CI}=0.42-0.94$; Table 3$)$.

\section{DISCUSSION}

Our annual survival rate estimate of $0.81(95 \% \mathrm{CI}=0.55-$ $0.94)$ is a biologically reasonable estimate and is close to the point estimates for each group in the second-ranked model, regardless of whether they were control or lightly hooked turtles. Although we found no difference between control and lightly hooked turtles with these data, it may be possible that a larger sample size would reduce the confidence intervals of estimates and allow differentiation between control and lightly hooked turtles. Our finding of no difference in time at the surface between the groups is consistent with what was observed by Swimmer et al. (2006) for olive ridley turtles in the eastern tropical Pacific Ocean.

We did not intend to estimate the mortality associated with a specific injury. Rather, we wanted to determine if there were differences in annual survival between injury classes. This is an important distinction as, unless the postinteraction mortality occurs immediately after the injury, fishery-induced mortality and natural mortality are confounded. In addition, it is possible that injured turtles have an increased susceptibility to predation that would further blur the distinction between fishery induced and natural mortality. Also, control turtles may subsequently interact with the fishery. Thus, the estimates that we compare are estimates of total annual mortality.

Unfortunately, we were unable to estimate survival for the entangled-only and swallowed-hook treatments. However, we assume entangled turtles that are released with all gear removed would have a survival probability of 0.81 . An 
Table 2. Akaike's Information Criterion adjusted for small sample sizes ( $\left.\mathrm{AIC}_{c}\right)$ values and weights, number of parameters, and deviance for impact category models from Program MARK for loggerhead turtles in the north-central Atlantic, 2001-2003.

\begin{tabular}{lccrr}
\hline Model & AIC $_{\boldsymbol{c}}$ & AIC $_{\boldsymbol{c}} \mathbf{w t}$ & No. of parameters & Deviance \\
\hline $\mathrm{S}(.)^{\mathrm{a}}$ & 32.437 & 0.725 & 1 & 12 \\
$\mathrm{~S}(\mathrm{~g})^{\mathrm{b}}$ & 34.378 & 0.275 & 12 & 10.660 \\
$\mathrm{~S}(\mathrm{t})^{\mathrm{c}}$ & 49.747 & 0.000 & 24 & 3.882 \\
$\mathrm{~S}(\mathrm{~g} \times \mathrm{t})^{\mathrm{d}}$ & 75.773 & 0.000 & & \\
\hline${ }^{\mathrm{a}}$ Constant survival by group and time. & & & \\
b Survival by group. & & & \\
c Survival by time. & & & \\
d Survival by group and time. & &
\end{tabular}

entangled but not hooked loggerhead is an uncommon interaction $(4 \%)$ in the United States pelagic longline fishery (Watson et al. 2005).

Our initial assessment of the group that swallowed the hooks suggests that survival rates may be lower than for the control and lightly hooked turtles, but sample size is much too small to produce estimates in which we have confidence. The PAT tags on the swallowed-hook turtles had an unusually high rate of failure to transmit. The cause may have been equipment failure; all the PATs we deployed on this group were Version 2, which has been reported to have a higher rate of failure to transmit than subsequent versions (Epperly et al., in press $a$ ). However, the failure rate of this group (6 of 10 did not transmit) is much higher than realized for the lightly hooked turtles ( 1 of 12 Version 2 tags failed to transmit) released the same year in the same area. We surmise that turtles that had swallowed the hook may have been at greater risk of predation and that the PAT tags were likely damaged during predation events. Riewald et al. (2005) found that turtles that swallowed the hooks did not swim strongly or utilize the water column to the extent utilized by dip-netted turtles, that they moved linearly with the currents (dip-netted turtles moved nonlinearly), and that these behavior differences spanned months postdeployment. Thus, turtles that swallowed the hook may be more vulnerable to predation while recuperating from the interaction or while dying.

Chaloupka et al. (2004) found that the time-specific mortality rate (e.g., time to transmitter failure) was much higher for turtles that swallowed a hook than that of lightly hooked turtles during the early part of the deployment $(90$ d) but were unable to determine if this was due to transmitter malfunctions, attachment failure, or early postrelease mortality. The survival rate of turtles that swallow the hook is an area of ongoing research but may prove to be problematic. If turtles that swallow hooks are more susceptible to predation resulting in tag damage and failure to transmit, we would not have the data necessary to estimate survival. Estimates based on the limited data received would be biased and overestimate annual survival for this group. Alternatively, if we assume all the failures to transmit are due to mortality, survival may be an underestimate as equipment failure is also a possibility.

The only estimate for pelagic survival comparable to the one we have calculated is that of Bjorndal et al. (2003). In that study, a catch-curve analysis of dip-netted loggerheads (our controls) was used to estimate annual survival. The turtles in our study correspond with the 6-12-year-old turtles of Bjorndal et al. (2003), which they estimated had an annual survival rate of 0.643 . Whereas Bjorndal et al. (2003) employed a well-known fishery harvest technique to estimate survival, our estimate may be more robust as it was derived from the remotely sensed data of individual fates via satellite transmission. However, their estimate is likely biased low, as variation in annual cohort sizes recruiting into the pelagic foraging population and emigration from the population were not considered.

We have provided an empirical estimate of survival for pelagic oceanic loggerheads $>43 \mathrm{~cm}$ which can be used in population modeling efforts and ultimately influence management decisions. The potential reduction in annual survival for turtles subjected to fishery interaction has been of concern to managers and the conservation community, but our data suggest that light hooking in the pelagic longline fishery may not result in a reduction in annual survival relative to controls.

Although these results indicate there is no detectable reduction, our sample sizes were small and research should continue to increase the precision of estimates and conclusively address the question for all injury classes, particularly for those turtles that have swallowed a hook. Ideally, a study of $\geq 2$ years would have a sample size of 40 50 turtles in each injury class in each year with PAT tags deployed in the same season and location, but this may not

Table 3. Monthly and annual survival estimates and 95\% confidence intervals of pelagic loggerhead turtles in the north-central Atlantic, 2001-2003.

\begin{tabular}{clccrr}
\hline Model & Impact category & Monthly survival & $\mathbf{9 5 \%}$ CI & Annual survival & 95\% CI \\
\hline $\mathrm{S}()$. & Not applicable & 0.98 & $0.95-0.99$ & 0.81 & $0.55-0.94$ \\
$\mathrm{~S}(\mathrm{~g})$ & Control & 0.99 & $0.91-0.99$ & 0.85 & $0.41-0.98$ \\
& Lightly hooked & 0.98 & $0.92-0.99$ & 0.78 & $0.42-0.94$ \\
\hline
\end{tabular}


be feasible given the prohibitive costs and logistic difficulties. In the absence of such a study, gradual building of sample size with the assumption there are no differences among years, as here and in Chaloupka et al. (2004), may be the only viable alternative.

\section{MANAGEMENT IMPLICATIONS}

Our results provide additional insight into the potential impacts of longline fishery interactions on loggerhead sea turtles and suggest that it may not be possible to distinguish survival rate differences between fishery-independent and lightly hooked turtles. The impact of light hooking can be quantified when assessing potential impacts of longline fisheries on loggerhead survival while the effect of other injury categories are not quantified at this time. Similar studies need to be completed to determine the survival rates of other categories of interactions, especially of animals that swallowed the hook.

\section{ACKNOWLEDGMENTS}

We wish to thank all the captains, crews, and vessel owners of Fishing Vessels Beth Anne, Bjorn II, Deesie, Destiny, Eagle Eye, Eagle Eye II, Eyelander, Hannah Lee, Karen L, Monica, Sea Hawk, Seneca, and Whitewater; Blue Water Fisherman's Association; National Marine Fisheries Service (NMFS) observers P. Bellew, J. Bemia, R. Brown, T. Droz, G. Hinteregger, N. Hopkins, D. Lawson, M. Maiellom B. Rhame, P. Rice, J. Rollo, J. Sheldon, J. Trew, C. J. Vaughn, and C. R. Wurster; NMFS personnel L. Belskis, L. Beerkircher, D. Lee, E. Prince, C. Rivero, and L. Stokes. Additionally, we wish to thank A. Bolten, M. Santos, and the late B. Riewald for their assistance in deploying tags in the Azores; and J. Caldwell for dip-netting the control turtles. Special thanks to J. Watson, the principal investigator of the gear experiments who facilitated this concurrent project. We wish to thank the anonymous reviewers for suggestions to improve this manuscript. National Marine Fisheries Service does not approve, recommend, or endorse any proprietary product or material mentioned in this publication. No reference shall be made to NMFS or to this publication in any advertising or sales promotion that would imply that NMFS approves, recommends, or endorses any proprietary product or proprietary material herein or which has as its purpose any intent to cause directly or indirectly the advertised produce to be used or purchased because of NMFS publication.

\section{LITERATURE CITED}

Bjorndal, K. A., A. B. Bolten, and H. R. Martins. 2003. Estimates of survival probabilities for oceanic-stage loggerhead sea turtles (Caretta caretta) in the North Atlantic. Fishery Bulletin 101:732-736.

Bolten, A. B., H. R. Martins, E. Isidoro, R. Ferreira, M. Santos, A. Giga, B. Riewald, and K. A. Bjorndal. 2004. Results of an experiment to evaluate effects of hook type on sea turtle bycatch in the swordfish longline fishery in the Azores. Page 42 in M. S. Coyne and R. D. Clark, compilers. Proceedings of the twenty-first annual symposium on sea turtle biology and conservation. National Oceanic and Atmospheric
Administration Technical Memorandum NMFS-SEFSC-528, Miami, Florida, USA.

Burnham, K. P., and D. R. Anderson. 1992. Data-based selection of an appropriate biological model: the key to modern data analysis. Pages 1630 in D. R. MucCullough and R. H. Barett, editors. Wildlife 2001: populations. Elsevier Applied Science, New York, New York, USA.

Burnham, K. P., and D. R. Anderson. 1998. Model selection and inference: a practical information theoretic approach. Springer-Verlag, New York, New York, USA.

Chaloupka, M. 2003. Stochastic simulation modeling of loggerhead sea turtle population dynamics given exposure to competing mortality risks in the western south Pacific region. Pages 274-294 in A. B. Bolten and B. E. Witherington, editors. Loggerhead sea turtles. Smithsonian, Washington, D.C., USA.

Chaloupka, M., D. Parker, and G. Balazs. 2004. Modelling post-release mortality of loggerhead turtles exposed to the Hawaii-based pelagic longline fishery. Marine Ecology Progress Series 280:285-293.

Crouse, D. T., L. B. Crowder, and H. Caswell. 1987. A stage-based population model for loggerhead sea turtles and implications for conservation. Ecology 68:1412-1423.

Crowder, L. B., D. T. Crouse, S. S. Heppell, and T. H. Martin. 1994. Predicting the impact of turtle excluder devices on loggerhead sea turtle populations. Ecological Applications 4:437-445.

Domeier, M. L., H. Dewar, and N. Nasby-Lucas. 2003. Mortality rate of striped marlin (Tetrapturus audax) caught with recreational tackle. Marine and Freshwater Research 54:443-445.

Dutton, D. L., P. H. Dutton, M. Chaloupka, and R. H. Boulon. 2005. Increase of a Caribbean leatherback turtle Dermochelys coriacea nesting population linked to long-term nest protection. Biological Conservation 126:186-194.

Epperly, S. P., C. Sasso, E. Prince, A. Bolten, J. Wyneken, J. Flanagan, C. Harms, and C. Rivero. In press $a$. Popup archival transmitting (PAT) tags and their application to loggerhead sea turtle survival studies. In P. Sheridan, J. W. Ferguson, and S. L. Downing, editors. Report of the National Marine Fisheries Service workshop on advancing the state of technology and use in stock assessment, 23-25 August 2005. National Oceanic and Atmospheric Administration Technical Memorandum, Seattle, Washington, USA.

Epperly, S. P., J. Wyneken, J. P. Flanagan, C. A. Harms, and B. Higgins. In press $b$. Attachment of pop-up archival transmitting (PAT) tags to loggerhead sea turtles (Caretta caretta). Herpetological Review.

Federal Register. 2004. Atlantic highly migratory species (HMS) pelagic fishery: final rule. July 6, 2004, 50 CFR Parts 223 and 635. Federal Register 69(128):40734-40758.

Hays, G. C., A. C. Broderick, B. J. Godley, P. Luschi, and W. J. Nichols. 2003. Satellite telemetry suggests high levels of fishing-induced mortality in marine turtles. Marine Ecology Progress Series 262:305-309.

Heppell, S. S., D. Crouse, L. Crowder, S. Epperly, W. Gabriel, T. Henwood, R. Marquez, and N. Thompson. 2005. A population model to estimate recovery time, population size, and management impacts on Kemp's ridleys. Chelonian Conservation and Biology 4:767-773.

Heppell, S. S., L. B. Crowder, D. T. Crouse, S. P. Epperly, and N. B. Frazier. 2003. Population models for Atlantic loggerheads: past, present, and future. Pages 255-273 in A. B. Bolten and B. E. Witherington, editors. Loggerhead sea turtles. Smithsonian Institution, Washington, D.C., USA.

Horodysky, A. Z., and J. E. Graves. 2005. Application of pop-up satellite archival tag technology to estimate postrelease survival of white marlin (Tetrapturus albidus) caught on circle and straight-shank ("J") hooks in the western North Atlantic recreational fishery. Fishery Bulletin 103:8496.

Hurvich, C. M., and C.-L. Tsai. 1989. Regression and time series model selection in small samples. Biometrika 76:297-307.

Lewison, R. L., S. A. Freeman, and L. B. Crowder. 2004. Quantifying the effects of fisheries on threatened species: the impact of pelagic longlines on loggerhead and leatherback sea turtles. Ecology Letters 7:221-231.

National Marine Fisheries Service. 2001. Stock assessments of loggerhead and leatherback sea turtles and an assessment of the impact of the pelagic longline fishery on loggerhead and leatherback sea turtles of the western north Atlantic. U.S. Department of Commerce, National Oceanic and 
Atmospheric Administration, Technical Memorandum NMFS-SEFSC455, Miami, Florida, USA.

Polovina, J. J., G. H. Balazs, E. A. Howell, D. M. Parker, M. P. Seki, and P. H. Dutton. 2004. Forage and migration habitat of loggerhead (Caretta caretta) and olive ridley (Lepidochelys olivacea) sea turtles in the central North Pacific Ocean. Fisheries Oceanography 13:36-51.

Riewald, B., A. B. Bolten, K. A. Bjorndal, and H. R. Martins. 2005. Effects of longline hooking on dive behavior and mortality of oceanic-stage juvenile loggerhead sea turtles (Caretta caretta). Page 298 in M. S. Coyne and R. D. Clark, compilers. Proceedings of the twenty-first annual symposium on sea turtle biology and conservation. U.S. Department of Commerce, National Oceanic and Atmospheric Administration Technical Memorandum NMFS-SEFSC-528, Miami, Florida, USA.

Ryder, C. E., T. A. Conant, and B. A. Schroeder. 2006. Report of the workshop on marine turtle longline post-interaction mortality. U.S.
Department of Commerce, National Oceanic and Atmospheric Administration Technical Memorandum NMFS-F/OPR-29, Silver Springs, Maryland, USA.

Swimmer, Y., R. Arauz, M. McCraken, L. McNaughton, J. Ballestero, M. Musyl, K. Bigelow, and R. Brill. 2006. Diving behavior and delayed mortality of olive ridley sea turtles Lepidochelys olivacea after their release from longline fishing gear. Marine Ecology Progress Series 323:253-261.

Watson, J. W., S. P. Epperly, A. K. Shah, and D. G. Foster. 2005. Fishing methods to reduce sea turtle mortality associated with pelagic longlines. Canadian Journal of Fisheries and Aquatic Science 62:965-981.

White, G. C., and K. P. Burnham. 1999. Program MARK: survival rate estimation from both live and dead encounters. Bird Study 46(Supplement):S123-S139.

Associate Editor: Greenberg. 